\title{
Curative and Protectant Activity of Fungicides for Control of Crown Rot of Strawberry Caused by Colletotrichum gloeosporioides
}

\author{
S. J. MacKenzie, J. C. Mertely, and N. A. Peres, University of Florida, Department of Plant Pathology, Gulf Coast \\ Research and Education Center, Wimauma, FL 33598
}

\begin{abstract}
MacKenzie, S. J., Mertely, J. C., and Peres, N. A. 2009. Curative and protectant activity of fungicides for control of crown rot of strawberry caused by Colletotrichum gloeosporioides. Plant Dis. 93:815-820.

The ability of fungicides to control Colletotrichum crown rot of strawberry caused by C. gloeosporioides was examined over three seasons. A single application of each fungicide was made 2 days before inoculation (2 DBI) or 1 day after inoculation (1 DAI) with conidial suspensions of C. gloeosporioides. The proportion of plants collapsed on one date at the end of each season was evaluated. In a combined analysis, there was a significant fungicide treatment-season interaction $(P=0.004)$. Percent mortality was $64 \%$ over 3 years in control plots that were inoculated with C. gloeosporioides but not treated with fungicide. Captan applied 2 DBI consistently reduced plant mortality (mean mortality $=17 \%$ ). However, it was not as effective when applied 1 DAI (mean mortality $=46 \%$ ). Azoxystrobin, pyraclostrobin, and thiophanate-methyl all reduced plant mortality relative to the control if applied 2 DBI (mean mortality $=46 \%$ for azoxystrobin, $37 \%$ for pyraclostrobin, and $41 \%$ for thiophanate-methyl) or 1 DAI (mean mortality $=29 \%$ for azoxystrobin, $27 \%$ for pyraclostrobin, and 32\% for thiophanate-methyl). Results indicated that these fungicides were more effective when applied 1 DAI; however, lower plant mortality was not always observed with postinoculation applications. Cyprodinil + fludioxonil reduced mortality relative to the control, but there was no consistent evidence that it was more effective when applied at 2 DBI (mean mortality $=39 \%$ ) than when applied 1 DAI (mean mortality $=40 \%)$. Similarly, mortality in plots treated with thiram 2 DBI (mean mortality $=30 \%$ ) or 1 DAI (mean mortality $=32 \%$ ) was not different. Potassium phosphite did not affect mortality, regardless of the timing of application (2 DBI mean mortality $=61 \%, 1$ DAI mean mortality $=67 \%$ ). The results indicated that an effective strategy for controlling Colletotrichum crown rot caused by C. gloeosporioides should be based on weekly applications of captan throughout the growing season. Azoxystrobin, pyraclostrobin, or thiophanate-methyl applications should be applied when weather conditions are highly favorable for disease development and the activity of contact fungicides such as captan or thiram might be compromised.
\end{abstract}

Colletotrichum crown rot of strawberry is caused by Colletotrichum gloeosporioides (12), C. fragariae (4,5), or $C$. acutatum (8). The disease is common in the southeastern United States where warm, year-round temperatures and abundant rainfall favor growth and dissemination of the pathogen. $C$. fragariae and $C$. gloeosporioides cause most of the Colletotrichum crown rot observed in this region (21), and C. gloeosporioides is the pathogen most commonly isolated from crowns in Florida (26). In other southeastern states, C. fragariae may account for a greater proportion of crown rot infections (23). C. fragariae and C. gloeosporioides produce a reddish brown necrosis of crown tissue that causes the plant to wilt and collapse. Necrosis is more limited in

Corresponding author: S. J. MacKenzie

E-mail: sjmac@ufl.edu

Accepted for publication 22 April 2009.

doi:10.1094/PDIS-93-8-0815

(C) 2009 The American Phytopathological Society crowns infected with $C$. acutatum, and if infected after establishment, plants are typically stunted rather than collapsed $(21,26)$.

The development of Colletotrichum crown rot symptoms caused by $C$. gloeosporioides and $C$. fragariae on plants is influenced by soil nitrogen fertility (20), temperature (22), and the level of disease resistance in the plant $(7,16)$. Plant colonization and disease spread may occur in low- to mid-elevation nurseries in the southeastern United States (21). Diseased plants shipped from these nurseries to Florida typically succumb to crown rot 1 to 2 months after transplant. In the past 5 years, there have been several instances where transplants from North Carolina either failed to establish or collapsed within the first month of the growing season, and C. gloeosporioides was routinely isolated from the transplants (J. C. Mertely, personal observation). Plant mortality in some fields approached 100\%. Nurseries in the northern United States and Canada or at high elevation are believed to lie outside the range of $C$. fragariae and $C$. gloeosporioides. Large losses of plants propagated in northern regions after being transplanted in Florida are rare, but a small proportion of plants from these regions are still affected by crown rot during the Florida growing season. These plants are probably infected after transplantation, and noncultivated or weed hosts growing close to strawberry fields are a likely source of primary inoculum for the infections (27). The time between infection and collapse of plants infected with $C$. fragariae or $C$. gloeosporioides ranges from 1 to 3 months during the Florida growing season, which lasts from October to late March (16). Multiple disease cycles could occur during the course of a single season under favorable weather conditions, but this appears to be rare. Symptom development is much faster during summer months, and multiple infection cycles are likely to occur in summer nurseries in Florida or elsewhere in the southeastern United States.

Colletotrichum crown rot is controlled primarily through the propagation of disease-free transplants (21). Cultivars with complete resistance to Colletotrichum crown rot are unknown, and the resistance that is observed in commercial cultivars may only prolong the time required for the plant to collapse (16). Growth of transplants on low fertility soil is another option to reduce disease development (20), but the reduced amount of disease is accompanied by decreases in runner production. In field experiments evaluating control of Colletotrichum crown rot caused by $C$. fragariae, benomyl and captafol gave excellent results $(6,11)$. However, isolates of both $C$. fragariae and $C$. gloeosporioides resistant to benzimidazole fungicides have developed in response to benomyl use $(18,24 ;$ S. J. MacKenzie, unpublished data), and registration of captafol for use on strawberry was never pursued (18). Inhibitors of sterol biosynthesis such as propiconazole and myclobutanil also provided good control of crown rot caused by C. fragariae (18). Protectant fungicides such as captan and chlorothalonil inhibit conidial germination and growth of $C$. fragariae in vitro (6), but their effectiveness under field conditions has not been clearly demonstrated $(11,18)$.

There is virtually no information available on chemical control of Colletotrichum crown rot caused by $C$. gloeosporioides. To provide information to growers on products and strategies to control this disease, we evaluated the pre- and post- 
infection activity of fungicides with different modes of action that are presently registered for use on strawberry.

\section{MATERIALS AND METHODS}

Field preparation, plant establishment, and plant maintenance. Bare-root strawberry plants (cv. Camarosa) were transplanted into plastic-mulched, raised beds at the Gulf Coast Research and Education Center in Dover, FL on 19 October 2004 for evaluation in the 2004-05 season and at the Gulf Coast Research and Education Center in Wimauma, FL on 26 October 2006 and 18 October 2007 for evaluation in the 2006-07 and 2007-08 seasons. For the 2004-05 and 2007-08 seasons, beds were fumigated with methyl bromide:chloropicrin $(98: 2)$ prior to transplant, and for the 2006-07 season beds were fumigated with methyl bromide:chloropicrin (67:33). The beds were $71 \mathrm{~cm}$ wide on 1.2-m centers. Each bed contained two staggered rows of plants spaced $38 \mathrm{~cm}$ apart within rows and $30 \mathrm{~cm}$ apart between rows. The transplants were irrigated by overhead sprinklers for 10 to 12 days to aid establishment. Following establishment, plants were irrigated and fertilized through drip tape as needed. Fruit were harvested from plants by hand weekly. Plots for treatment evaluations were $4.25 \mathrm{~m}$ long and contained 20 plants, with 10 plants in each of two rows.

Inoculum preparation and application. C. gloeosporioides isolate 98-285 was used for all inoculations. This isolate displays the Cgl-2 AT-rich DNA banding pattern described by Freeman et al. (9) in a study of two $C$. gloeosporioides subpopulations on strawberry and is sensitive to benomyl. Isolates with the $\mathrm{Cgl}-2$ genotype comprise the subpopulation responsible for most Colletotrichum crown rot infections in Florida (17), and isolate 98-285 was moderately aggressive compared to other isolates in a trial evaluating cultivars for resistance to Colletotrichum crown rot (16). Conidial suspensions used for inoculations were prepared from 6- to 8-day-old cultures grown under continuous fluorescent light at $24^{\circ} \mathrm{C}$ on potato dextrose agar. Conidia were washed from plates with sterile distilled water and the conidial suspension was passed through four layers of cheesecloth. In a previous study, inoculations with $5 \times 10^{5}$ conidia/ml were used to evaluate cultivars for resistance to Colletotrichum crown rot (16). This amount of inoculum was not available from the cultures on dates when weather conditions were conducive to infection, so the amount of inoculum applied each season was maximized by diluting conidia with water to a volume just sufficient to inoculate all of the plots. The final conidial concentrations of these dilutions were $1.0 \times 10^{5}$ conidia/ml for inoculations on 6 December $2004,1.6 \times 10^{5}$ conidia/ml for inoculations on 14 December 2006 , and $2.0 \times 10^{5}$ co- nidia/ml for inoculations on 29 November 2007. Conidial suspensions, without added surfactant, were applied to the plants with a $\mathrm{CO}_{2}$ backpack sprayer calibrated to deliver 935 liters/ha at $275 \mathrm{kPa}$ through a two-nozzle boom. Immediately following inoculations, the nighttime wetness interval was $13.25 \mathrm{~h}$ in $2004,16.75 \mathrm{~h}$ in 2006 , and $15.5 \mathrm{~h}$ in 2007 . Average temperatures over these intervals ranged from 19.8 to $20.3^{\circ} \mathrm{C}$. Wetness intervals for the three nights following inoculations exceeded 12 $\mathrm{h}$, and average temperatures during these succeeding intervals exceeded $17.5^{\circ} \mathrm{C}$.

Fungicide applications. Following establishment of the transplants, the trial area received weekly maintenance applications of captan (Captan 80WDG; Micro Flo Company LLC, Memphis, TN) at $1.65 \mathrm{~kg}$ a.i./ha applied by a tractor-mounted hydraulic sprayer until 1 week prior to the application of the fungicides to be evaluated for control of Colletotrichum crown rot. Fungicides evaluated for the control of Colletotrichum crown rot were commercial formulations of the systemically distributed chemicals azoxystrobin (Abound 2.08F; Syngenta Crop Protection, Inc., Greensboro, NC) at $0.280 \mathrm{~kg}$ a.i./ha, pyraclostrobin (Cabrio 20EG; BASF Corporation, Research Triangle Park, NC) at 0.196 $\mathrm{kg}$ a.i./ha, thiophanate-methyl (Topsin M 70WP or 4.5F; Cerexagri-Nisso LLC, King of Prussia, PA) at $0.785 \mathrm{~kg}$ a.i./ha (70WP) or $0.788 \mathrm{~kg}$ a.i./ha $(4.5 \mathrm{~F})$, and potassium phosphite (ProPhyt; Helena Chemical Company, Collierville, TN, or K-Phite; Plant Food Systems, Inc., Zellwood, FL) at $2.348 \mathrm{~kg}$ a.i./ha (ProPhyt) or $2.417 \mathrm{~kg}$ a.i./ha (K-Phite); nonsystemic fungicides thiram (Thiram Granuflo 75WDG; Taminco, Inc., Atlanta, GA) at $3.363 \mathrm{~kg}$ a.i./ha and captan (Captan 80WDG; Micro Flo Company LLC, Memphis, TN) at $3.287 \mathrm{~kg}$ a.i./ha; and a combination of a systemically distributed fungicide cyprodinil and a nonsystemic fungicide fludioxonil (Switch 62.5WG; Syngenta) with fungicide concentrations of $0.363 \mathrm{~kg}$ a.i./ha and $0.245 \mathrm{~kg}$ a.i./ha, respectively. All fungicides were evaluated all three seasons (2004-05, 2006-07, and 200708), except thiram and potassium phosphite, which were not evaluated during the 2004-05 season. With the exception of potassium phosphite treatments, treatments consisted of a single application of each fungicide made 2 days before inoculation (2 DBI) or 1 day after inoculation (1 DAI). The applications 2 DBI were made on 4 December 2004, 12 December 2006, and 27 November 2007 for fungicide evaluations made during the 2004-05, 2006-07, and 2007-08 seasons, respectively. The applications 1 DAI were made on 7 December 2004, 15 December 2006, and 30 November 2007 for fungicide evaluations made during the 2004-05, 2006-07, and 2007-08 seasons, respectively. Potassium phosphite was applied in three applications made 21 days apart, with the first application at 2 DBI (12 December 2006 for the 2006-07 season and 27 November 2007 for the 2007-08 season) or 1 DAI (15 December 2006 for the 2006-07 season and 30 November 2007 for the 2007-08 season). Treatments were applied with a $\mathrm{CO}_{2}$ backpack sprayer calibrated to deliver 935 liters/ha at $275 \mathrm{kPa}$ through a two-nozzle boom. To suppress secondary disease spread between plots, captan was applied to all plots weekly from a tractor-mounted hydraulic sprayer beginning 1 week after the inoculations (1.65 kg a.i./ha until late season bloom, $2.63 \mathrm{~kg}$ a.i./ha once bloom began).

Experimental design, data collection, and statistical analysis. Treatments were arranged in a randomized complete block design with seven blocks. Each block consisted of a single bed. Each combination of fungicide and application time was considered a treatment. During the 2004-05 season, a plot that would have received azoxystrobin at 2 DBI and a plot that would have received captan at 1 DAI were not inoculated; therefore, this season there were only six replicates for these two treatments. In addition to fungicide-treated plots, a control inoculated with C. gloeosporioides and a noninoculated control were located in each block. Neither the inoculated nor the noninoculated control was treated with the test fungicides. During specified weeks, the proportion of dead and totally collapsed plants was recorded for each plot. Data were collected 5, 7, 9, 11 , and 15 weeks after inoculation (WAI) from 10 January to 21 March 2005 for the 2004-05 season; 4, 6, 8, 10, 12, and 14 WAI from 8 January to 23 March 2007 for the 2006-07 season; and 4, 6, 8, 10, 12, 14, and 16 WAI from 27 December 2007 to 20 March 2008 for the 2007-08 season. These data were used to assess disease progression in plots. Data from a single weekly interval were used for statistical analysis each season. The week chosen for analysis had the highest among treatment variance that season. Prior to analysis, data from individual plots were transformed to the arcsine square root. The formula for the transformation was $\arcsin \{\operatorname{sqrt}[(y+$ $3 / 8) /(n+3 / 4)]\}$, where $y=$ the number of collapsed plants per plot and $n=$ the total number of plants per plot (2). The noninoculated control was excluded from all statistical analyses. Data for the three seasons were analyzed separately and combined using PROC MIXED of SAS (SAS Institute, Cary, NC). Fungicide treatment (each fungicide-application time combination) was considered a fixed effect. Block was considered a random effect in the analyses examining seasons separately. In the analysis examining seasons combined, season, block(season), and season $\times$ treatment were considered random effects. Overall treatment effects were evaluated with $F$ statistics and random effects with 
2004-2005
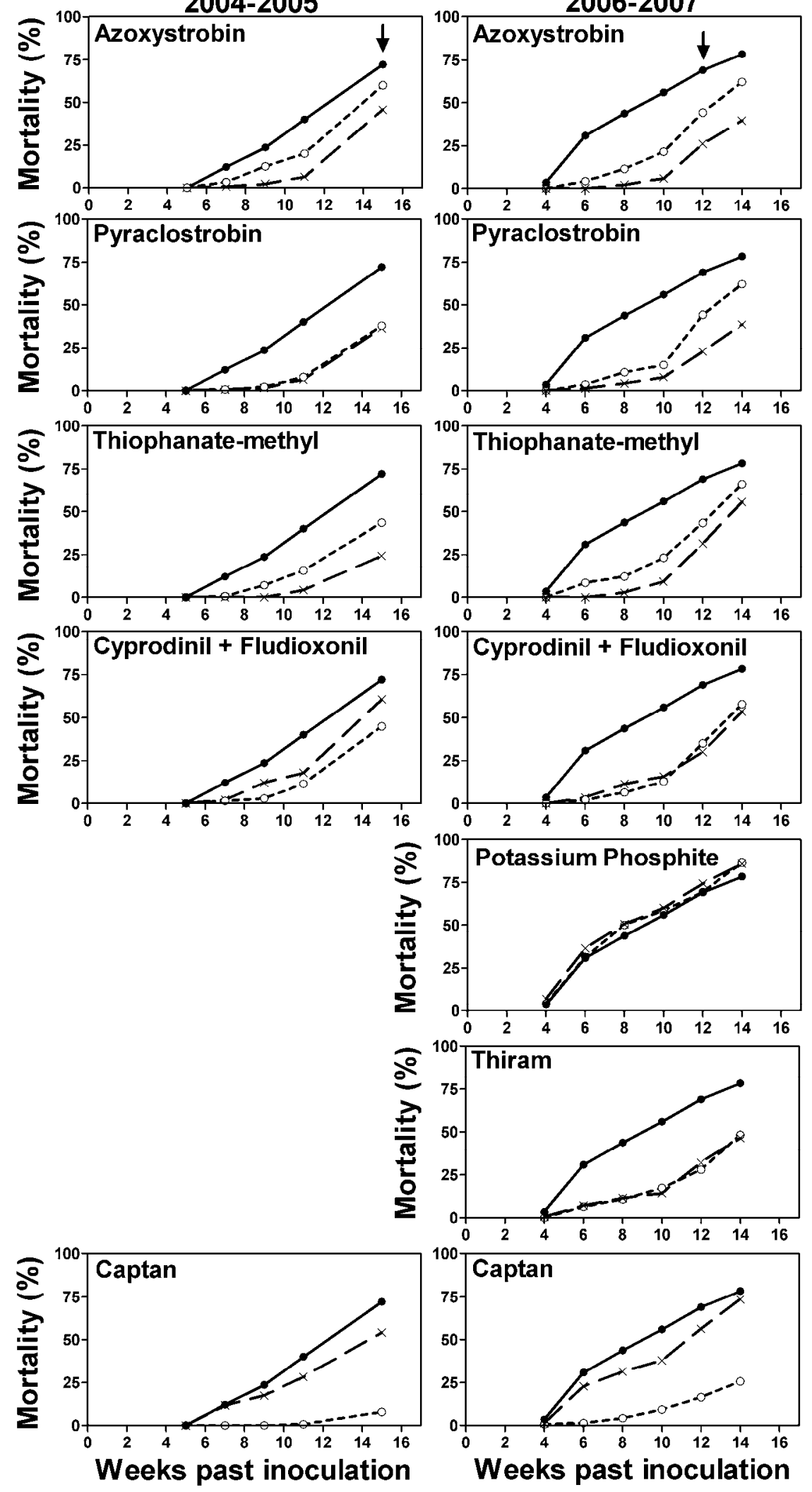

2006-2007
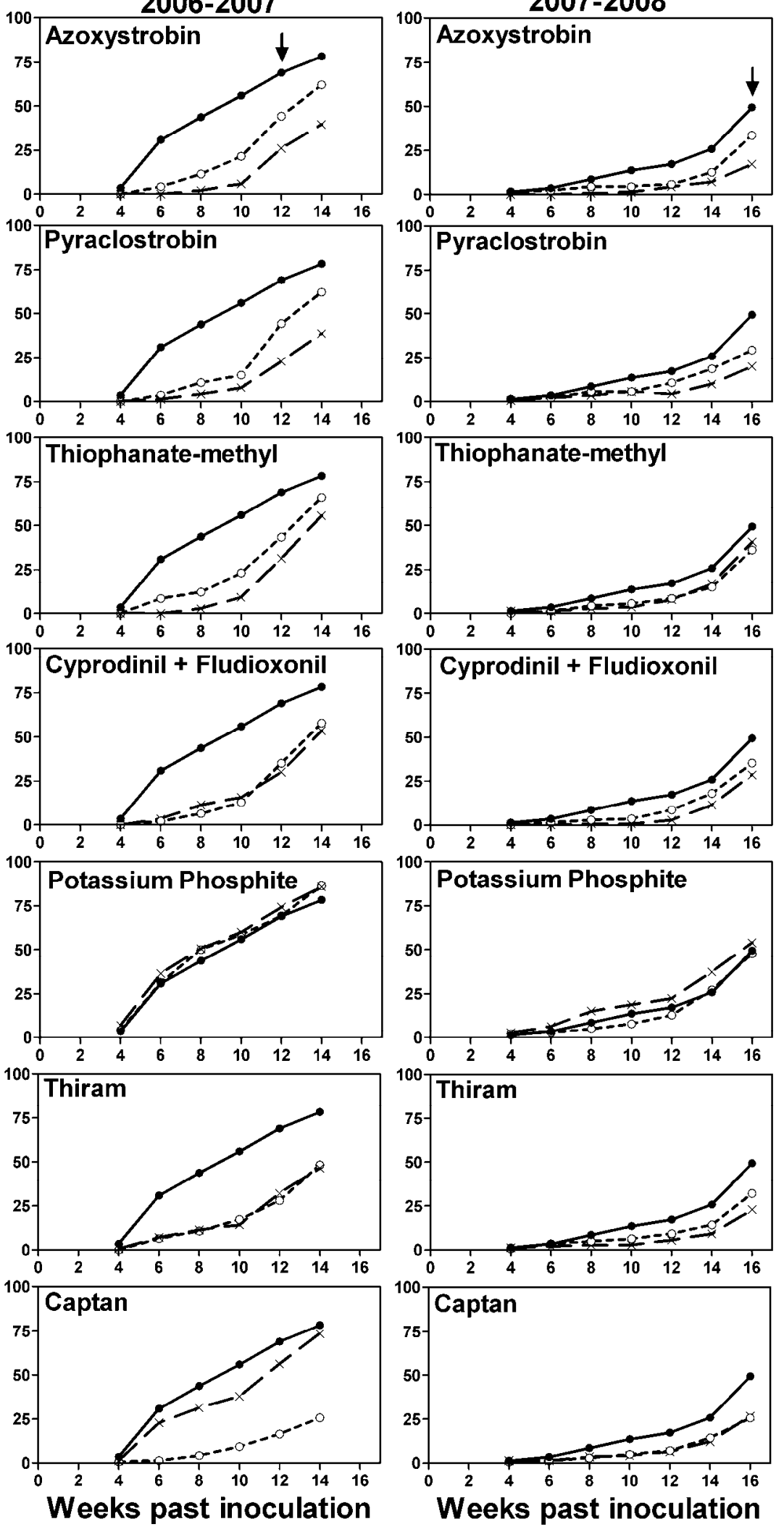

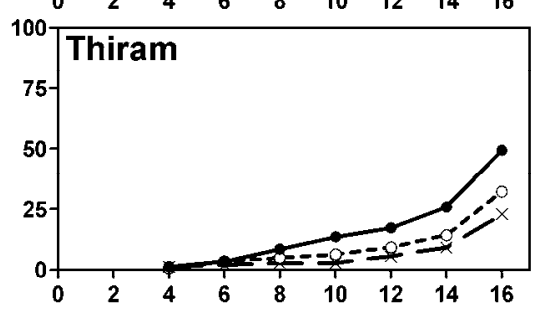

2007-2008
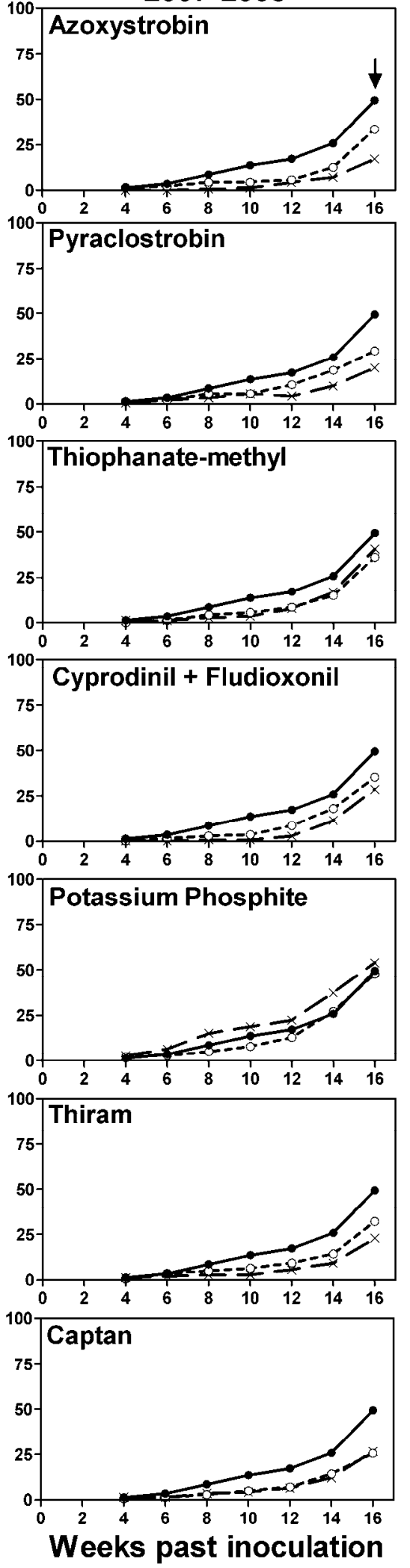

\section{$\rightarrow$ Control $\cdot \cdots \cdot 2$ days before inoculation $* 1$ day after inoculation}

Fig. 1. Mean percent strawberry plant mortality in plots treated with azoxystrobin, pyraclostrobin, thiophanate-methyl, cyprodinil + fludioxonil, potassium phosphite, thiram, or captan either 2 days before or 1 day after inoculation with Colletotrichum gloeosporioides during the 2004-05, 2006-07, and 2007-08 seasons compared to inoculated control plots not treated with fungicide. Mortality is shown over intervals beginning 5 (2004-05) or 4 (2006-07 and 200708) weeks after inoculation and ending 15 (2004-05), 14 (2006-07), or 16 (2007-08) weeks after inoculation. The arrows ( $\rightarrow$ ) on the graphs for azoxystrobin in the top row indicate the week during the season that mortality data were used for statistical analysis. 
$Z$ statistics. The $Z$ statistic was calculated by dividing the estimated variance component for each random effect by the standard deviation of each estimate. Differences for fungicide treatments were evaluated using the LSMEANS statement and PDIFF option.

\section{RESULTS}

During all three experiments, plants began to collapse 4 weeks after inoculation, and the percentage of collapsed plants continued to increase until experiments were terminated 15 WAI for the 2004-05 season, 14 WAI for the 2006-07 season, and 16 WAI for the 2007-08 season (Fig. $1)$. The rankings of the before or after inoculation applications were consistent between evaluations for each test product (Fig. 1). Data from week 15 in 2004-05, week 12 in 2006-07, and week 16 in 2007-08 were used for statistical analysis. The back-transformed mean percent plant mortality in inoculated control plots at these time points was $71.7,69.0$, and $49.4 \%$ for the 2004-05, 2006-07, and 2007-08 seasons, respectively. There were no obvious environmental factors such as poor weather conditions for infection following inoculations or sustained low temperatures during the season that could explain differences in disease incidences across seasons, nor did disease incidence correlate with the concentration of inoculum applied. The contribution of inoculum spray drift, secondary spread, or crown rot caused by a pathogen other than that used for inoculations to plant mortality was low each season, with mean crown rot incidence of $1.4 \%$ in $2004-05,4.3 \%$ in 200607 , and $1.4 \%$ in $2007-08$ in noninoculated control plots. Analyses were conducted to determine if fungicides reduced mortality relative to that found in inoculated plots that did not receive fungicide (Table 1), to determine if application timing affected plant mortality for each fungicide treatment (Table 1), and to compare the overall effectiveness of the different fungicide and application time combinations (Table 2). The $F$ statistics for overall treatment effect for seasons analyzed separately or combined were all significant at $P<0.001$ $\left(F_{10,58}=15.48\right.$ for $2004-05, F_{14,84}=17.10$ for $2006-07, F_{14,84}=5.31$ for 2007-08, and $F_{14,24}=5.36$ for seasons combined). For each season, the residual variance of transformed mortality incidence was similar (0.0167 for 2004-05, 0.0146 for 2006$07,0.0173$ for $2007-08$, and 0.0162 for the combined analysis). The variance estimate for block was not statistically different from 0 based on $Z$-scores $(P>0.05)$ for each season analyzed separately. The variance component block(season) was significantly different from zero $\left(\sigma^{2}\right.$ block(season) $=0.00348, Z=2.21 ; P=0.013)$ when data from all three seasons were combined. Although the variance component for season was not significantly different from zero $\left(\sigma_{\text {season }}^{2}=0.00356, Z=0.72 ; P=\right.$ 0.235 ), the variance component of season $\times$ treatment was $\left(\sigma^{2}\right.$ seasonxtreatment $=$ $0.008307, Z=2.70 ; P=0.004)$. No environmental factor could be identified that might explain the season $\times$ treatment interaction.

For all three seasons tested, cyprodinil + fludioxonil applications made 2 DBI, azoxystrobin applications made 1 DAI, and pyraclostrobin or captan applications made at either 2 DBI or 1 DAI significantly $(P<0.05)$ reduced plant mortality (Table 1). Azoxystrobin applied 2 DBI, cyprodinil + fludioxonil applied 1 DAI, and thiophanate-methyl applications made at 2 DBI or 1 DAI significantly reduced plant mortality in two of three seasons. Although plant mortality in plots treated with azoxystrobin at 2 DBI in 2004-05, cyprodinil + fludioxonil at 1 DAI in 200405 , and thiophanate-methyl at either $2 \mathrm{DBI}$ or 1 DAI in 2007-08 was not significantly different from plant mortality in control plots, there was some decline in mortality. For treatments tested only in 2006-07 and 2007-08, thiram applied 2 DBI or 1 DAI significantly reduced plant mortality both seasons (Table 1). Potassium phosphite, applied either before or after inoculation, did not significantly reduce plant mortality either season tested.

Application timing effects were most dramatic for azoxystrobin, for which a significant difference between fungicide applications made 2 DBI and 1 DAI was observed each season (Table 1). Plant mortality was consistently lower when azoxystrobin was applied 1 DAI. The other QoI fungicide, pyraclostrobin, significantly reduced plant mortality when applied 1 DAI compared to 2 DBI in the 2006-07 season (Table 1). During the 2004-05 and 2007-08 seasons, mortality was also lower when pyraclostrobin was applied 1 DAI, but the effect was not significant. Among the other treatments with systemic action, thiophanate-methyl-treated plots had significantly less mortality if the fungicide was applied at 1 DAI in 2004-05 (Table 1). However, in the other two seasons, the differences were not significant. Timing of potassium phosphite applications had no effect on plant mortality either season (Table 1). A timing effect of cyprodinil + fludioxonil was not clear. During the 2004-05 season, plant mortality was lower if the product was applied 2 DBI (Table 1). During the other two seasons, mortality was higher in plots treated 2 DBI, but differences were not significant. Among nonsystemic fungicides, only captan showed a significant effect of timing. Applications of captan made 2 DBI reduced plant mortality more than those made 1 DAI during the 2004-05 and 2006-07 seasons. There was no effect of application time in 2007-08. No significant differences were observed between thiram applications made 2 DBI and 1 DAI, nor was there a trend that would suggest a difference between application times.

Both residual and season $\times$ treatment variance components were used to estimate variances for means across seasons, and because the season $\times$ treatment variance component was high, variances of means calculated over multiple seasons were greater than those for means calculated within a season. However, even with the added uncertainty introduced by the season $x$ treatment interaction, several trends were evident from comparisons. Data from all three seasons indicated that captan was one of the most effective fungicides for control of Colletotrichum crown rot if applied before an infection event, but the product was less effective if applied after infection had occurred (Table 2). Azoxystrobin and pyraclostrobin were generally as effective as captan if applied after inoculation. However, relative to other treatments, the QoI fungicides were not as effective if applied preventively. Thiophanate-methyl was moderately effective for controlling crown rot if applied before or after inoculation, but control did not appear to be as good as with preventive applications of captan. Thiram was also effective compared to other treatments, regardless of the time applied. It was not significantly different from captan applied before inoculation. However, because thiram treatments were only conducted over two seasons, pairwise comparisons involving these treatments had reduced statistical power. The cyprodinil + fludioxonil product, applied either before or after inoculation, gave intermediate control of crown rot.

\section{DISCUSSION}

Captan applied before an infection event consistently reduced crown rot to levels equal to or below that observed for other fungicide treatments. In previous field experiments, scheduled applications of captan did not appear to control strawberry crown rot caused by $C$. fragariae $(6,18)$. However, consistent with our results, in unpublished trials (S. J. MacKenzie) captan applied at a 7-day interval throughout the growing season reduced mortality caused by $C$. gloeosporioides from 32.1 to $2.1 \%$ when infected plants within the plot were the source of inoculum, and from 21.7 to $0.9 \%$ when the source of inoculum was from outside the plot.

Captan and thiram were the only fungicide treatments in this study that lacked systemic activity. Both reduced disease relative to the control when applied after inoculation as well as before, which suggested that these protectants could have some effect on disease if applied within 24 $\mathrm{h}$ after an infection event. However, efficacy was greatly reduced if captan was applied after rather than before inoculation in 2 of 3 years. Thiram was as effective if applied before inoculation or after in both seasons tested, suggesting that its curative 
activity may be of longer duration than captan, although previous reports do not indicate that thiram has any systemic activity (25).

Fungicides with at least some systemic activity reduced crown rot as preventive or as curative treatments. Azoxystrobin was more effective if applied after inoculation.
The data suggest that pyraclostrobin and thiophanate-methyl are more effective when applied after infection than before, but for each fungicide this trend was statistically significant for only one season. Although both azoxystrobin and pyraclostrobin target the same site, azoxystrobin is more mobile within plants relative to pyra- clostrobin, which may explain the lower efficacy of azoxystrobin when applied preventively (3). Thiophanate-methyl was more effective if applied after inoculation for only one season, and there was no apparent trend the other two seasons. Although it has systemic activity compared to other benzimidazole fungicides, rela-

Table 1. Mean ${ }^{\mathrm{w}}$ crown rot incidence in fungicide-treated strawberry plots compared to nonsprayed control plots inoculated with Colletotrichum gloeosporioides and comparison of mean crown rot incidence between plots treated with a fungicide 2 days before inoculation (DBI) and 1 day after inoculation $(\mathrm{DAI})^{\mathrm{x}}$ with C. gloeosporioides

\begin{tabular}{|c|c|c|c|c|c|c|c|}
\hline \multirow[b]{2}{*}{ Treatment } & \multirow[b]{2}{*}{$\begin{array}{c}\text { Time of } \\
\text { application }\end{array}$} & \multicolumn{2}{|c|}{ 2004-05 } & \multicolumn{2}{|c|}{ 2006-07 } & \multicolumn{2}{|c|}{ 2007-08 } \\
\hline & & $\begin{array}{l}\text { Crown rot } \\
\text { incidence }^{w, y}\end{array}$ & $\begin{array}{c}1 \text { DAI - } 2 \text { DBI } \\
\text { crown rot } \\
\text { incidence }\end{array}$ & $\begin{array}{l}\text { Crown rot } \\
\text { incidence }^{w, y}\end{array}$ & $\begin{array}{l}1 \text { DAI - } 2 \text { DBI } \\
\text { crown rot } \\
\text { incidence } \\
\text {,y,y }\end{array}$ & $\begin{array}{l}\text { Crown rot } \\
\text { incidence }^{w, y}\end{array}$ & $\begin{array}{c}1 \text { DAI - } 2 \text { DBI } \\
\text { crown rot } \\
\text { incidence }\end{array}$ \\
\hline Control (no treatment) & & $71.7(1.01)$ & & $69.0(0.981)$ & & $49.4(0.780)$ & \\
\hline \multirow[t]{2}{*}{ Azoxystrobin } & $2 \mathrm{DBI}$ & $60.8(0.895)$ & $-15.5(-0.156)^{*}$ & $44.4(0.729)^{* * *}$ & $-18.2(-0.192)^{* *}$ & $32.9(0.611)^{*}$ & $-15.5(-0.181)^{*}$ \\
\hline & $1 \mathrm{DAI}$ & $45.3(0.739) * * *$ & & $26.2(0.537) * * *$ & & $17.4(0.430)^{* * *}$ & \\
\hline \multirow[t]{2}{*}{ Pyraclostrobin } & $2 \mathrm{DBI}$ & $37.8(0.663)^{* * *}$ & $-1.6(-0.017)$ & $44.4(0.729)^{* * *}$ & $-20.9(-0.223) * * *$ & $29.7(0.576)^{* *}$ & $-9.2(-0.106)$ \\
\hline & $1 \mathrm{DAI}$ & $36.2(0.645)^{* * *}$ & & $23.5(0.506)^{* * *}$ & & $20.5(0.470)^{* * *}$ & \\
\hline \multirow[t]{2}{*}{ Thiophanate-methyl } & 2 DBI & $43.7(0.722)^{* * *}$ & $-18.9(-0.200)^{* *}$ & $43.0(0.715)^{* * * *}$ & $-11.4(-0.118)$ & $36.1(0.644)$ & $4.7(0.049)$ \\
\hline & $1 \mathrm{DAI}$ & $24.8(0.522) * * *$ & & $31.6(0.597)^{* * *}$ & & $40.8(0.693)$ & \\
\hline \multirow[t]{2}{*}{ Cyprodinil + fludioxonil } & $2 \mathrm{DBI}$ & $44.9(0.735)^{* * *}$ & $15.8(0.158)^{*}$ & $35.4(0.638) * * *$ & $-5.1(-0.055)$ & $35.5(0.639)^{*}$ & $-6.4(-0.069)$ \\
\hline & $1 \mathrm{DAI}$ & $60.7(0.893)$ & & $30.3(0.582) * * *$ & & $29.1(0.570)^{* *}$ & \\
\hline \multirow[t]{2}{*}{ Potassium phosphite } & $2 \mathrm{DBI}$ & $\ldots$ & $\ldots$ & $69.2(0.983)$ & $5.9(0.063)$ & $47.7(0.762)$ & $6.3(0.063)$ \\
\hline & $1 \mathrm{DAI}$ & $\ldots$ & & $74.9(1.046)$ & & $54.0(0.826)$ & \\
\hline \multirow[t]{2}{*}{ Thiram } & $2 \mathrm{DBI}$ & $\ldots$ & $\ldots$ & $28.1(0.558)^{* * * *}$ & $4.3(0.047)$ & $31.8(0.600)^{*}$ & $-9.2(-0.104)$ \\
\hline & $1 \mathrm{DAI}$ & $\ldots$ & & $32.4(0.606)^{* * *}$ & & $22.6(0.496)^{* * *}$ & \\
\hline \multirow[t]{2}{*}{ Captan } & $2 \mathrm{DBI}$ & $9.1(0.307) * * *$ & $45.1(0.521)^{* * *}$ & $16.9(0.424) * * *$ & $39.3(0.424)^{* * *}$ & $26.3(0.539) * *$ & $1.0(0.011)$ \\
\hline & $1 \mathrm{DAI}$ & $54.2(0.828)^{*}$ & & $56.2(0.847)^{*}$ & & $27.3(0.550)^{* *}$ & \\
\hline \multicolumn{2}{|l|}{$\operatorname{LSD}(P \leq 0.05)^{\mathrm{z}}$} & \multicolumn{2}{|c|}{$0.138,0.144$} & \multicolumn{2}{|c|}{0.129} & \multicolumn{2}{|c|}{0.140} \\
\hline
\end{tabular}

${ }^{w}$ Mean crown rot incidence for each treatment is reported as percent mortality, which was calculated by back-transforming the mean arcsine square root disease incidence for each treatment that is reported in parentheses. Mortality data collected at 15, 12, and 16 weeks after inoculation were used for the 2004-05 season, 2006-07 season, and 2007-08 season, respectively.

${ }^{x}$ Differences in crown rot incidence between 1 DAI and 2 DBI applications of the same chemical were calculated from back-transformed percentages. In parentheses, differences between mean transformed values are reported.

y Treatment means significantly different from the nontreated control at $P<0.05, P<0.01$, and $P<0.001$ and 1 DAI -2 DBI crown rot incidences significantly different from zero at $P<0.05, P<0.01$, and $P<0.001$ are indicated by $*, * *$, and $* * *$, respectively.

${ }^{\mathrm{z}}$ LSD value for the 2004-05 season was 0.138 for all pairwise comparisons except comparisons to azoxystrobin applied at 2 DBI and captan at 1 DAI where the LSD value was 0.144 . These differences are for transformed means shown in parentheses.

Table 2. Comparison of mean ${ }^{w}$ crown rot incidence in strawberry plots treated with fungicide 2 days before inoculation (DBI) or 1 day after inoculation (DAI) with Colletotrichum gloeosporioides

\begin{tabular}{|c|c|c|c|c|c|}
\hline Fungicide & Time of application & Seasons combined $d^{\mathrm{w}, \mathrm{x}, \mathrm{y}}$ & $2004-05^{w, x}$ & $2006-07^{w, x}$ & $2007-08^{w, x}$ \\
\hline Captan & $2 \mathrm{DBI}$ & $16.8(0.423) \mathrm{a}$ & $9.1(0.307) \mathrm{a}$ & $16.9(0.424) \mathrm{a}$ & $26.3(0.539)$ abcd \\
\hline Pyraclostrobin & $1 \mathrm{DAI}$ & $26.5(0.540) a b$ & $36.2(0.645) \mathrm{bc}$ & $23.5(0.506) \mathrm{ab}$ & $20.5(0.470) \mathrm{ab}$ \\
\hline Azoxystrobin & $1 \mathrm{DAI}$ & $29.0(0.569) \mathrm{abc}$ & $45.3(0.739) \mathrm{cd}$ & $26.2(0.537) \mathrm{abc}$ & $17.4(0.430) \mathrm{a}$ \\
\hline Thiram & $1 \mathrm{DAI}$ & $29.7(0.577)$ abcd & $\ldots$ & $32.4(0.606)$ bcde & $22.6(0.496) \mathrm{abc}$ \\
\hline Thiophanate-methyl & $1 \mathrm{DAI}$ & $32.3(0.604) \mathrm{bcd}$ & $24.8(0.522) b$ & $31.6(0.597) \mathrm{bcd}$ & $40.8(0.693)$ efgh \\
\hline Thiram & $2 \mathrm{DBI}$ & $32.3(0.605)$ abcd & $\ldots$ & $28.1(0.558) b c$ & $31.8(0.600)$ bcde \\
\hline Pyraclostrobin & $2 \mathrm{DBI}$ & $37.2(0.656) \mathrm{bcd}$ & $37.8(0.663) \mathrm{c}$ & $44.4(0.729)$ ef & $29.7(0.576)$ bcde \\
\hline Cyprodinil + fludioxonil & $2 \mathrm{DBI}$ & $38.6(0.670) \mathrm{bcd}$ & $44.9(0.735) \mathrm{cd}$ & $35.4(0.638) \mathrm{cde}$ & $35.5(0.639)$ def \\
\hline Cyprodinil + fludioxonil & $1 \mathrm{DAI}$ & $39.7(0.682) \mathrm{bcd}$ & $60.7(0.893)$ ef & $30.3(0.582) b c$ & $29.1(0.570)$ abcde \\
\hline Thiophanate-methyl & $2 \mathrm{DBI}$ & $40.9(0.694) \mathrm{bcd}$ & $43.7(0.722) \mathrm{cd}$ & $43.0(0.715) \mathrm{de}$ & $36.1(0.644)$ defg \\
\hline Captan & $1 \mathrm{DAI}$ & $45.6(0.741) \mathrm{cde}$ & $54.2(0.828) \mathrm{de}$ & $56.2(0.847) \mathrm{f}$ & $27.3(0.550)$ abcd \\
\hline Azoxystrobin & $2 \mathrm{DBI}$ & $45.8(0.743) \mathrm{de}$ & $60.8(0.895)$ ef & $44.4(0.729)$ ef & $32.9(0.611) \mathrm{cde}$ \\
\hline Potassium phosphite & $2 \mathrm{DBI}$ & $61.2(0.899)$ ef & $\ldots$ & $69.2(0.983) \mathrm{g}$ & $47.7(0.762) \mathrm{fgh}$ \\
\hline Control (no treatment) & & $63.6(0.924) \mathrm{f}$ & $71.7(1.010) \mathrm{f}$ & $69.0(0.981) \mathrm{g}$ & $49.4(0.780) \mathrm{gh}$ \\
\hline Potassium phosphite & 1 DAI & $67.3(0.962) \mathrm{f}$ & $\ldots$ & $74.9(1.046) \mathrm{g}$ & $54.0(0.826) \mathrm{h}$ \\
\hline $\operatorname{LSD}(P \leq 0.05)^{\mathrm{z}}$ & & $0.174,0.175,0.196,0.212$ & $0.138,0.144,0.150$ & 0.129 & 0.140 \\
\hline
\end{tabular}

${ }^{\mathrm{w}}$ Mean crown rot incidence for each treatment is reported as percent mortality, which was calculated by back-transforming the mean arcsine square root disease incidence for each treatment that is reported in parentheses. Mortality data collected at 15, 12, and 16 weeks after inoculation were used for the 2004-05 season, 2006-07 season, and 2007-08 season, respectively.

${ }^{\mathrm{x}}$ Means within the same column followed by the same letter were not significantly different $(P=0.05)$ according to least square means $t$ tests.

${ }^{y}$ Means for seasons combined were estimated from fixed effect model parameters, and variances of these means were estimated from treatment $\times$ year and residual variance components.

${ }^{\mathrm{z}}$ For the three seasons combined, the LSD equal to 0.174 was used to compare treatments included in trials all three seasons except the comparison between azoxystrobin applied at 2 DBI and captan at 1 DAI, where an LSD equal to 0.175 was used. An LSD equal to 0.196 was used to compare treatments included in trials three seasons to those included for two seasons, and an LSD equal to 0.212 was used to compare treatments included in trials during two seasons only. For the 2004-05 season, the LSD value of 0.138 was used for all comparisons except those that included treatments azoxystrobin applied at 2 DBI and captan at 1 DAI. Comparisons involving these treatments used an LSD of 0.144 and 0.150 when they were compared to each other. 
tively high levels of thiophanate-methyl may persist on plant surfaces up to $48 \mathrm{~h}$ after application (19). Similar to the results for pyraclostrobin, the persistence of thiophanate-methyl at the plant surface may explain the absence of a timing effect some seasons.

For diseases caused by a group of ascomycetes, the timing of cyprodinil applications did not appear to affect disease control if applications were made a few days before or after inoculations (14). The relatively wide window that cyprodinil can be applied and provide effective disease control could account for the lack of consistent differences between the 2-DBI and 1DAI fungicide applications in the combined cyprodinil + fludioxonil treatment. However, given that fludioxonil is a contact fungicide, its inclusion in a mixture should have improved control for preinoculation treatments. This may explain the results observed in 2004-05, where the 2-DBI application was more effective than the 1-DAI application.

Except where noted, fungicide effects were in good agreement with trials examining diseases caused by $C$. gloeosporioides on crops other than strawberry and in vitro studies. Azoxystrobin, pyraclostrobin, thiophanate-methyl, and fludioxonil all reduced the incidence of postharvest anthracnose of tangerine caused by C. gloeosporioides when applied 2 days before harvest (29). Treatment of lupine seed with thiram reduced transmission of anthracnose caused by $C$. gloeosporioides to plants (25). Abril et al. (1) found that cyprodinil was strongly inhibitory to the germination and growth of C. gloeosporioides in vitro. Zainuri et al. (28) showed that potassium phosphite does not directly interfere with $C$. gloeosporioides infection of mango fruit. Our results also indicate that potassium phosphite does not directly interfere with the ability of $C$. gloeosporioides to infect strawberry. Potassium phosphite potentially can reduce disease by activating a plant's chemical defenses (13). Although we found no effect of potassium phosphite on crown rot, the preinoculation application was made only 2 days before inoculation, which may not have been sufficient time for an activated defense response.

Captan is typically included in scheduled fungicide applications for control of a variety of strawberry diseases in Florida (15). In this state, fields with transplants from a source outside of the range of $C$. gloeosporioides typically have a low incidence of Colletotrichum crown rot, and scheduled captan sprays are normally suf- ficient to control the disease during the relatively cool growing season. In nurseries located in areas where $C$. gloeosporioides is present and weather conditions are often conducive to rapid spread of disease, captan or thiram should be included in a scheduled program to control crown rot caused by $C$. gloeosporioides since the risk for resistance development is low (10). When applied after infection, fungicides with some systemic activity generally were more effective. These fungicides act on a single site, may be more expensive, and are more restricted with respect to the number of applications allowed. However, they may be useful in a management program when applied after weather events that are favorable for disease development and detrimental to the activity of protectant fungicides which may have been applied.

\section{LITERATURE CITED}

1. Abril, M., Curry, K. J., Smith, B. J., and Wedge, D. E. 2008. Improved microassays used to test natural product-based and conventional fungicides on plant pathogenic fungi. Plant Dis. 92:106-112.

2. Anscombe, F. J. 1948. The transformation of poisson, binomial and negative-binomial data. Biometrika 35:246-254.

3. Bartlett, D. W., Clough, J. M., Godwin, J. R., Hall, A. A., Hamer, M., and Par-Dobrzanski, B. 2002. The strobilurin fungicides. Pest Manag. Sci. 58:649-662.

4. Brooks, A. N. 1931. Anthracnose of strawberry caused by Colletotrichum fragariae, $\mathrm{n}$. sp. Phytopathology 21:739-744.

5. Brooks, A. N. 1935. Anthracnose and wilt of strawberry caused by Colletotrichum fragariae. (Abstr.) Phytopathology 25:973-974.

6. Delp, B. R., and Milholland, R. D. 1980. Control of strawberry anthracnose with captafol. Plant Dis. 64:1013-1015.

7. Delp, B. R., and Milholland, R. D. 1981. Susceptibility of strawberry cultivars and related species to Colletotrichum fragariae. Plant Dis. 65:421-423.

8. Freeman, S., and Katan, T. 1997. Identification of Colletotrichum species responsible for anthracnose and root necrosis of strawberry in Israel. Phytopathology 87:516-521.

9. Freeman, S., Pham, M., and Rodriguez, R. J. 1993. Molecular genotyping of Colletotrichum species based on arbitrarily primed PCR, A+Trich DNA, and nuclear DNA analyses. Exp. Mycol. 17:309-322

10. Fungicide Resistance Action Committee. 2007. FRAC code list: Fungicides sorted by mode of actions (including FRAC code numbering). http://www.frac.info/frac/publication/anhang/F RAC_Code_List_2007_web.pdf

11. Howard, C. M. 1971. Control of strawberry anthracnose with benomyl. Plant Dis. Rep. 55:139-141.

12. Howard, C. M., and Albregts, E. E. 1984. Anthracnose of strawberry fruit caused by Glomerella cingulata in Florida. Plant Dis. 68:824-825.

13. Jackson, T. J., Burgess, T., Colquhoun, I., and Hardy, G. E. StJ. 2000. Action of the fungicide phosphite on Eucalyptus marginata inoculated with Phytophthora cinnamomi. Plant Pathol. 49:147-154.

14. Knauf-Beiter, G., Dahmen, H., Heye, U., and Staub, T. 1995. Activity of cyprodinil: Optimal treatment timing and site of action. Plant Dis. 79:1098-1103.

15. Legard, D. E., MacKenzie, S. J., Mertely, J. C., Chandler, C. K., and Peres, N. A. 2005. Development of a reduced use fungicide program for control of Botrytis fruit rot on annual winter strawberry. Plant Dis. 89:1353-1358.

16. MacKenzie, S. J., Legard, D. E., Timmer, L. W., Chandler, C. K., and Peres, N. A. 2006. Resistance of strawberry cultivars to crown rot caused by Colletotrichum gloeosporioides isolates from Florida is nonspecific. Plant Dis. 90:1091-1097.

17. MacKenzie, S. J., Seijo, T. E., Legard, D. E., Timmer, L. W., and Peres, N. A. 2007. Selection for pathogenicity to strawberry in populations of Colletotrichum gloeosporioides from native plants. Phytopathology 97:1130-1140.

18. McInnes, T. B., Black, L. L., and Gatti, Jr., J. M. 1992. Fungicides for control of strawberry anthracnose crown rot in summer nurseries. Adv. Strawberry Res. 11:12-16.

19. Shillingford, C. A., and Sinclair, J. B. 1978. Uptake and translocation of systemic fungicides by banana fruits as determined by assay. Plant Dis. Rep. 62:1107-1111.

20. Smith, B. J. 1987. Effect of nitrogen, phosphorus, and potassium on the severity of strawberry anthracnose-crown rot. (Abstr.) Phytopathology 77:1691.

21. Smith, B. J. 2008. Epidemiology and pathology of strawberry anthracnose: A North American perspective. HortScience 43:69-73.

22. Smith, B. J., and Black, L. L. 1987. Resistance of strawberry plants to Colletotrichum fragariae affected by environmental conditions. Plant Dis. 71:834-837.

23. Smith, B. J., and Black, L. L. 1990. Morphological, cultural, and pathogenic variation among Colletotrichum species isolated from strawberry. Plant Dis. 74:69-76.

24. Smith, B. J., and Black, L. L. 1993. In vitro fungicide studies show the occurrence of benomyl-resistant Colletotrichum spp. from strawberry. Adv. Strawberry Res. 12:42-48.

25. Thomas, G. J. 2003. Fungicide seed treatments reduce seed transmission and severity of lupin anthracnose caused by Colletotrichum gloeosporioides. Australas. Plant Pathol. 32:39-46.

26. Ureña-Padilla, A. R., MacKenzie, S. J., Bowen, B. W., and Legard, D. E. 2002. Etiology and population genetics of Colletotrichum spp. causing crown and fruit rot of strawberry. Phytopathology 92:1245-1252.

27. Xiao, C. L., MacKenzie, S. J., and Legard, D. E. 2004. Genetic and pathogenic analyses of Colletotrichum gloeosporioides isolates from strawberry and noncultivated hosts. Phytopathology 94:446-453.

28. Zainuri, J. D. C., Wearing, A. H., Coates, L., and Terry, L. 2001. Effects of phosphonate and salicylic acid treatments on anthracnose disease development and ripening of 'Kensington Pride' mango fruit. Aust. J. Exp. Agric. 41:805-813.

29. Zhang, J., and Timmer, L. W. 2007. Preharvest application of fungicides for postharvest disease control on early season tangerine hybrids in Florida. Crop Prot. 26:1449-1458. 